\title{
Continuous intravenous epoprostenol for chronic thromboembolic pulmonary hypertension
}

\author{
P. Bresser*, P.F. Fedullo", W.R. Auger", R.N. Channick", I.M. Robbins ${ }^{\Uparrow}$, K.M. Kerr", S.W. Jamieson ${ }^{+}$, \\ L.J. Rubin"
}

Continuous intravenous epoprostenol for chronic thromboembolic pulmonary hypertension. P. Bresser, P.F. Fedullo, W.R. Auger, R.N. Channick, I.M. Robbins, K.M. Kerr, S.W. Jamieson, L.J. Rubin. (C)ERS Journals Ltd 2004.

ABSTRACT: Pathophysiological findings in chronic thromboembolic pulmonary hypertension (CTEPH) have suggested that a secondary small vessel arteriopathy may contribute to the haemodynamic impairment observed in these patients. It was hypothesised that this element of the elevated vascular resistance may be responsive to continuous intravenous epoprostenol therapy.

Retrospectively, the clinical and haemodynamic responses to continuous intravenous epoprostenol were evaluated in nine CTEPH patients who subsequently underwent pulmonary thromboendarterectomy (PTE). Cardiopulmonary haemodynamics were determined prior to the initiation of epoprostenol, while on epoprostenol, prior to PTE, and after PTE.

Six patients, treated for 2-26 months prior to PTE, experienced either clinical stability or improvement that was associated with a mean reduction in pulmonary vascular resistance (PVR) of $28 \%$ (median 33\%, range $0-46 \%$ ). Three patients, treated for 3-9 months, experienced clinical deterioration during epoprostenol administration, with a significant increase in PVR in two patients. Subsequent PTE resulted in a highly significant improvement of cardiac index, mean pulmonary artery pressure and total pulmonary resistance.

To conclude, selected patients with chronic thromboembolic pulmonary hypertension may benefit clinically and haemodynamically from continuous intravenous epoprostenol treatment prior to pulmonary thromboendarterectomy. Factors predictive of a beneficial response, and whether this intervention influences either morbidity or mortality associated with pulmonary thromboendarterectomy, remain to be established. Eur Respir J 2004; 23: 595-600.
*Dept of Pulmonology, Academic Medical Centre, Amsterdam, the Netherlands. ${ }^{\#}$ Division of Pulmonary and Critical Care Medicine, ${ }^{+}$Division of Cardiothoracic Surgery, University of California San Diego, San Diego, CA, and "Division of Allergy, Pulmonology and Critical Care Medicine, Vanderbilt University School of Medicine, Nashville, TN, USA

Correspondence: P. Bresser, Academic Medical Centre, University of Amsterdam, Dept of Pulmonology, F5-162, PO Box 22700, 1100 DE Amsterdam, the Netherlands.

Fax: 3120691784

E-mail: p.bresser@amc.uva.nl

Keywords: Chronic thromboembolic pulmonary hypertension

epoprostenol

pulmonary thromboendartectomy

right heart failure

Received: February 232003

Accepted after revision: November 32003

I.M. Robbins was supported by NIH grant RR 15534.
Chronic thromboembolic pulmonary hypertension (CTEPH) results from the incomplete resolution of the pulmonary vascular obstruction associated with acute pulmonary embolism. Pulmonary hypertension early in the disease is a direct consequence of this loss of the pulmonary vascular bed due to the central obstruction. Over time, however, gradual haemodynamic and symptomatic decline has been observed in certain patients that appears to be related to the development of a secondary pulmonary hypertensive arteriopathy in the small precapillary pulmonary vessels $[1,2]$. By contributing to the elevated pulmonary vascular resistance (PVR), this arteriopathy adversely affects cardiac function and may potentially contribute to the haemodynamic instability encountered in patients following pulmonary thromboendarterectomy (PTE).

The prostacyclin analogue epoprostenol is widely used in the treatment of several forms of pulmonary arterial hypertension (PAH), including primary pulmonary hypertension (PPH) and the PAH associated with connective tissue disease [3-7], Eisenmenger's syndrome [8, 9], human immunodeficiency virus infection [10], Gaucher's disease [11], and portopulmonary hypertension [8, 12]. Little is known, however, about the effects of epoprostenol treatment in patients with CTEPH.

In this article, experience of continuous intravenous epoprostenol use in the management of nine patients with CTEPH prior to PTE is described.

\section{Methods}

A total of 246 patients underwent PTE for CTEPH at the University of California, San Diego (UCSD), USA, during the years 2000 and 2001. Nine of these patients were treated for various periods of time with continuous intravenous epoprostenol prior to thromboendarterectomy. In all nine patients, the diagnosis of CTEPH and baseline cardiopulmonary haemodynamics were determined by pulmonary angiography and right heart catheterisation prior to the initiation of epoprostenol. An acute vasodilator trial was performed in eight patients, using inhaled nitric oxide in six, intravenous adenosine in one, and intravenous epoprostenol in one. Prior to thromboendarterectomy, all patients underwent a repeat right heart catheterisation while still receiving epoprostenol therapy. A third set of haemodynamic measurements was obtained on the first or second day following the thromboendarterectomy procedure. Since insufflation of the Swan-Ganz catheter balloon within the pulmonary artery is contraindicated after thromboendarterectomy due to risk of 
suture line disruption, a pulmonary capillary wedge pressure was not obtained and PVR could not be calculated. Therefore, the total pulmonary resistance $\left(\mathrm{TPR} ; \operatorname{dyn} \cdot \mathrm{s}^{-1} \cdot \mathrm{cm}^{-5}\right)$ was used for comparison (mean pulmonary artery pressure (mPAP; $\mathrm{mmHg}) /$ cardiac output $\left.\left(\mathrm{L} \cdot \mathrm{min}^{-1}\right) \times 80\right)$.

\section{Statistical analysis}

The effects of treatment were analysed by the nonparametric Wilcoxon signed rank test. $p$-Values were corrected for multiple comparisons. A $\mathrm{p}<0.05$ was considered statistically significant.

\section{Results}

The clinical and haemodynamic characteristics of the nine patients are summarised in tables 1 and 2. All patients had complained of shortness of breath for at least 6 months prior to diagnosis. All patients were treated with oral anticoagulants after the diagnosis of pulmonary embolism had been established; all patients but one (patient E) were treated with oral anticoagulants for $\geqslant 3$ months prior to the start of the epoprostenol treatment. In two patients, the diagnosis of CTEPH was made after they presented with a 6-month history of persistent shortness of breath following an acute onset. In three patients, the diagnosis was made when they presented with slowly progressive exertional dyspnoea in the setting of recurrent, documented episodes of pulmonary embolism. In the remaining four patients, there was no historical evidence to suggest a prior thromboembolic event. The diagnosis of pulmonary embolism was made by pulmonary angiography following their presentation with gradually progressive dyspnoea and signs of right ventricular failure.
Three patients were considered by the referring physicians to suffer from surgically inaccessible thromboembolic disease at the time of diagnosis. Epoprostenol therapy was initiated in these patients because of a gradually progressive clinical decline despite conventional medical treatment. Four patients presented with signs of overt right-sided heart failure; epoprostenol treatment was started in three of these patients immediately after the diagnosis of CTEPH had been established to improve haemodynamics prior to anticipated surgical treatment. In two patients, PTE surgery was postponed after initial evaluation for thromboendarterectomy. In these patients, the likelihood that a significant haemodynamic improvement could be achieved by PTE, based on the angiographic and angioscopic findings, was estimated to be $<50 \%$.

\section{Haemodynamic characteristics}

Haemodynamic measurements prior to initiation of epoprostenol are summarised in table 1. All patients had severe pulmonary hypertension, with a median mPAP of $54 \mathrm{mmHg}$, and in the eight patients in which it was calculated, a median PVR of $1,031 \mathrm{dyn} \cdot \mathrm{s}^{-1} \cdot \mathrm{cm}^{-5}$. In one patient a satisfactory pulmonary capillary wedge pressure measurement could not be obtained and the PVR, therefore, could not be calculated. In this patient, the TPR was $3,022 \mathrm{dyn} \cdot \mathrm{s}^{-1} \cdot \mathrm{cm}^{-5}$. Severe cardiac dysfunction was present with a cardiac index $<2.0 \mathrm{~L} \cdot \mathrm{min}^{-1} \cdot \mathrm{m}^{-2}$ (median $1.5 \mathrm{~L} \cdot \mathrm{min}^{-1} \cdot \mathrm{m}^{-2}$ ) in six patients, and pulmonary artery $\mathrm{O}_{2}$ saturation $<65 \%$ (median $48 \%$ ) in all patients (table 1). Increased right atrial pressure (RAP), indicating right ventricular failure, was noted in five (table 1).

The nine patients received epoprostenol for a mean duration of 10.9 months (median 4 months) at a mean dose of $19.6 \mathrm{ng} \cdot \mathrm{kg}^{-1} \cdot \mathrm{min}^{-1}$ (median $18 \mathrm{ng} \cdot \mathrm{kg}^{-1} \cdot \mathrm{min}^{-1}$; table 2). Pulmonary vasoreactivity was not present in the eight patients

Table 1.-Clinical and haemodynamic characteristics at baseline

\begin{tabular}{|c|c|c|c|c|c|c|}
\hline Patient & NYHA & mPAP $\mathrm{mmHg}$ & Cardiac index $\mathrm{L} \cdot \mathrm{min}^{-1} \cdot \mathrm{m}^{-2}$ & PVR/TPR dyn $\cdot \mathrm{s}^{-1} \cdot \mathrm{cm}^{-5}$ & mRAP mmHg & $S_{\mathrm{v}, \mathrm{O}_{2}} \%$ \\
\hline A & III & $102 / 35(59)$ & 2.1 & $1168 / 1349$ & 12 & 62 \\
\hline B & III & $78 / 30(48)$ & 2.1 & $665 / 873$ & 10 & 64 \\
\hline $\mathrm{C}$ & III & $69 / 28(41)$ & 1.5 & $704 / 993$ & 6 & 57 \\
\hline D & IV & $62 / 26(42)$ & 0.9 & $914 / 1600$ & 24 & 40 \\
\hline E & IV & 129/38 (68) & 0.9 & ND/3022 & 14 & 35 \\
\hline $\mathrm{F}$ & IV & $118 / 46(77)$ & 2.4 & $1172 / 1432$ & 18 & 39 \\
\hline G & IV & $78 / 27(46)$ & 1.5 & $933 / 1226$ & 15 & 48 \\
\hline $\mathrm{H}$ & III & $108 / 29(56)$ & 1.6 & $1128 / 1445$ & 3 & 58 \\
\hline I & III & $83 / 32(54)$ & 1.2 & $1376 / 1728$ & 7 & 55 \\
\hline
\end{tabular}

NYHA: New York Heart Association; mPAP: mean pulmonary artery pressure; PVR: pulmonary vascular resistance; TPR: total pulmonary resistance; mRAP: mean right atrial pressure; $\mathrm{S}_{\mathrm{v}} \mathrm{O}_{2}$ : mixed venous oxygen saturation; ND: not determined.

Table 2.-Characteristics of epoprostenol treatment

\begin{tabular}{|c|c|c|c|c|c|c|}
\hline Patient & Age/sex & Duration $^{\#}$ months & Time months & Duration $^{+}$months & Epoprostenol dosage $\mathrm{e}^{\S} \mathrm{ng} \cdot \mathrm{kg}^{-1} \cdot \mathrm{min}^{-1}$ & Clinical response \\
\hline A & $58 / \mathrm{M}$ & 24 & 12 & 26 & 29 & Stable \\
\hline $\mathrm{B}$ & $43 / \mathrm{M}$ & 12 & 3 & 25 & 21 & Stable \\
\hline $\mathrm{C}$ & $59 / \mathrm{M}$ & 12 & 6 & 22 & 21 & Stable \\
\hline $\mathrm{D}$ & $37 / \mathrm{F}$ & 6 & 12 & 3 & 18 & Improvement \\
\hline $\mathrm{E}$ & $45 / \mathrm{M}$ & 9 & $<1$ & 2 & 10 & Improvement \\
\hline $\mathrm{F}$ & $34 / \mathrm{F}$ & 36 & $<1$ & 4 & 12 & Improvement \\
\hline G & $54 / \mathrm{M}$ & 12 & $<1$ & 4 & 18 & Progression \\
\hline $\mathrm{H}$ & $27 / \mathrm{M}$ & 8 & 4 & 9 & 31 & Progression \\
\hline I & $59 / \mathrm{F}$ & 6 & 6 & 3 & 16 & Progression \\
\hline
\end{tabular}

M: male; F: female; ${ }^{\#}$ : of symptoms prior to diagnosis; ${ }^{\uparrow}:$ between diagnosis and start of epoprostenol; ${ }^{+}$: of epoprostenol therapy; ${ }^{\S}$ : prior to endarterectomy. 

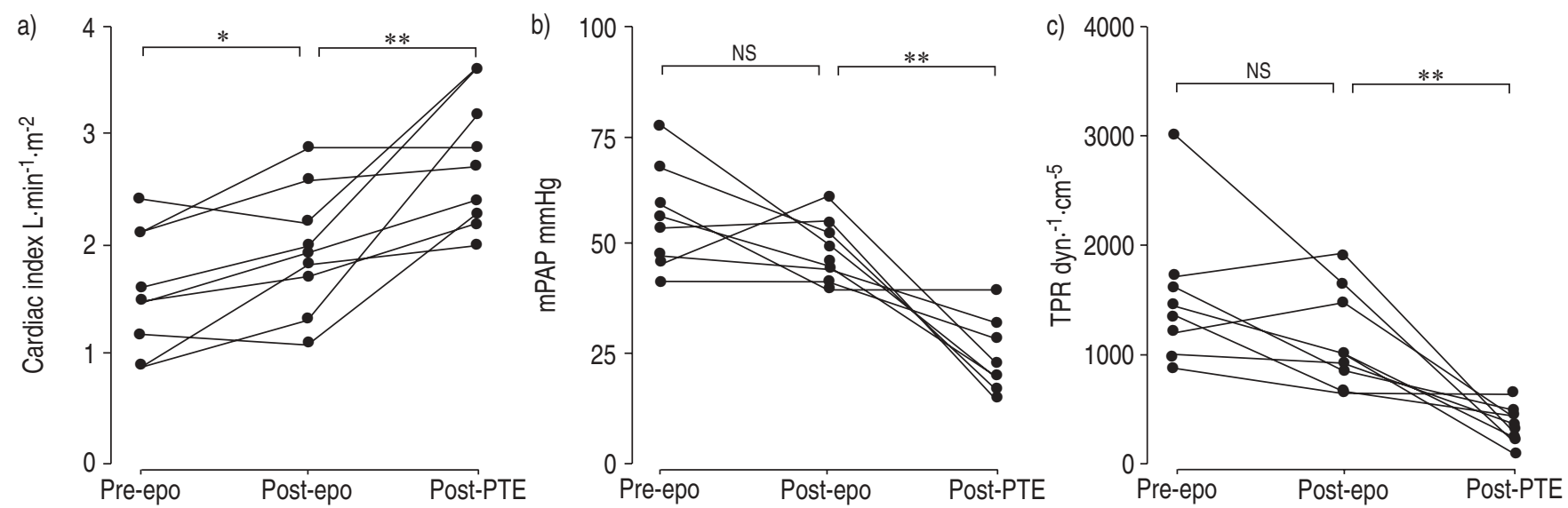

Fig. 1. - Individual haemodynamic characteristics $(n=9)$ prior to initiation of epoprostenol (pre-epo), while on epoprostenol prior to pulmonary thromboendarterectomy (PTE; post-epo), and after PTE (post-PTE). a) Cardiac index, b) mean pulmonary artery pressure (mPAP), and c) total pulmonary resistance (TPR) are shown. NS: nonsignificant; *: $\mathrm{p}<0.05 ; * *$ : $<<0.01$.

tested. Effects of epoprostenol treatment are shown in figure 1, and individual data are summarised in tables 3 and 4. Epoprostenol treatment was associated with a significant improvement in cardiac index, whereas the mPAP did not change significantly (fig. 1).

Prior to the initiation of the epoprostenol treatment, all patients were classified as New York Heart Association III/IV or IV/IV (table 1). Six patients (patients A-F) experienced either clinical stability or clinical improvement (table 4). The clinical response to epoprostenol treatment was most striking in three patients (patients $\mathrm{D}-\mathrm{F}$ ) who reported a significant improvement in their functional status and exercise tolerance (table 4). This clinical improvement was accompanied by a mean 34\% reduction (range $21-46 \%$ ) in PVR, and a mean $40 \%$ reduction (range $30-48 \%$ ) in TPR (table 3 ). In addition, in two of these patients (patients D and F) a significant reduction of RAP and an increase in mixed venous oxygen saturation $\left(\mathrm{S}_{\mathrm{v}}, \mathrm{O}_{2}\right)$ was observed (table 4$)$. In patient $\mathrm{F}$,

Table 3. - Haemodynamic measurement before (I) and during (II) therapy with epoprostenol

\begin{tabular}{|c|c|c|c|c|c|c|}
\hline Patient & $\begin{array}{l}\text { mPAP I } \\
\mathrm{mmHg}\end{array}$ & $\begin{array}{c}\text { mPAP II } \\
\text { mmHg }\end{array}$ & $\begin{array}{c}\text { Cardiac index I } \\
\mathrm{L} \cdot \mathrm{min}^{-1} \cdot \mathrm{m}^{-2}\end{array}$ & $\begin{array}{l}\text { Cardiac index II } \\
\mathrm{L} \cdot \mathrm{min}^{-1} \cdot \mathrm{m}^{-2}\end{array}$ & $\begin{array}{l}\text { PVR/TPR I } \\
\text { dyn } \cdot \mathrm{s}^{-1} \cdot \mathrm{cm}^{-5}\end{array}$ & $\begin{array}{l}\text { PVR/TPR II } \\
\mathrm{dyn}^{-1} \cdot \mathrm{s}^{-1} \cdot \mathrm{cm}^{-5}\end{array}$ \\
\hline \multicolumn{7}{|c|}{ Clinical stability } \\
\hline A & $102 / 35(59)$ & $69 / 22(40)$ & 2.1 & 2.9 & $1168 / 1349$ & $633 / 667$ \\
\hline $\mathrm{B}$ & $78 / 30(48)$ & $72 / 27(45)$ & 2.1 & 2.6 & $665 / 873$ & $593 / 667$ \\
\hline $\mathrm{C}$ & $69 / 28(41)$ & $77 / 29(48)$ & 1.5 & 1.9 & $704 / 993$ & $705 / 914$ \\
\hline \multicolumn{7}{|c|}{ Clinical improvement } \\
\hline D & $62 / 26(42)$ & $65 / 30(42)$ & 0.9 & 1.8 & $914 / 1600$ & $720 / 840$ \\
\hline $\mathrm{E}$ & $129 / 38(68)$ & $87 / 36(53)$ & 0.9 & 1.3 & $\mathrm{ND} / 3022$ & $1323 / 1631$ \\
\hline $\mathrm{F}$ & $118 / 46(77)$ & $95 / 15(50)$ & 2.4 & 2.2 & $1172 / 1432$ & $760 / 1000$ \\
\hline \multicolumn{7}{|c|}{ Clinical progression } \\
\hline $\mathrm{G}$ & $78 / 27(46)$ & $91 / 45(61)$ & 1.5 & 1.7 & $933 / 1226$ & $1236 / 1469$ \\
\hline $\mathrm{H}$ & $108 / 29(56)$ & $78 / 28(46)$ & 1.6 & 2.0 & $1128 / 1445$ & $978 / 1022$ \\
\hline I & $83 / 32(54)$ & $81 / 40(55)$ & 1.2 & 1.1 & $1376 / 1728$ & $1628 / 1913$ \\
\hline
\end{tabular}

mPAP: mean pulmonary artery pressure; PVR: pulmonary vascular resistance; TPR: total pulmonary resistance; ND: not determined.

Table 4. - Haemodynamic measurement and New York Heart Association (NYHA) classification before (I) and during (II) therapy with epoprostenol

\begin{tabular}{|c|c|c|c|c|c|c|}
\hline Patient & mRAP I mmHg & mRAP II mmHg & $S_{\mathrm{v}, \mathrm{O}_{2}} \mathrm{I} \%$ & $S_{\mathrm{v}, \mathrm{O}_{2}}$ II $\%$ & NYHA I & NYHA II \\
\hline \multicolumn{7}{|c|}{ Clinical stability } \\
\hline A & 12 & 12 & 62 & 47 & III & III \\
\hline $\mathrm{B}$ & 10 & 4 & 64 & 75 & III & III \\
\hline $\mathrm{C}$ & 6 & 9 & 57 & 70 & III & III \\
\hline \multicolumn{7}{|c|}{ Clinical improvement } \\
\hline $\mathrm{D}$ & 24 & 15 & 40 & 56 & IV & III \\
\hline $\mathrm{E}$ & 14 & 14 & 35 & 47 & IV & III \\
\hline $\mathrm{F}$ & 18 & 5 & 39 & 64 & IV & III \\
\hline \multicolumn{7}{|c|}{ Clinical progression } \\
\hline $\mathrm{G}$ & 15 & 27 & 48 & ND & IV & IV \\
\hline $\mathrm{H}$ & 3 & 16 & 58 & 49 & III & IV \\
\hline I & 7 & 13 & 55 & ND & III & III \\
\hline
\end{tabular}

mRAP: mean right atrial pressure; $\mathrm{S}_{\mathrm{v}}, \mathrm{O}_{2}$ : mixed venous oxygen saturation; $\mathrm{ND}$ : not determined. 
however, despite the increase in $\mathrm{S}_{\mathrm{v}} \mathrm{O}_{2}$ during treatment, a decrease in cardiac output was observed. This discrepancy could not be explained fully. Furthermore, two of these patients (patients D and E) experiencing lightheadedness and syncope prior to the start of treatment had resolution of these symptoms while receiving epoprostenol. Three patients experienced clinical stability during a prolonged period of epoprostenol administration (patients $\mathrm{A}-\mathrm{C}$; table 4). In one of these patients, the PVR/TPR remained stable over a 22month period. In the other two patients experiencing clinical stability, a reduction in PVR/TPR was demonstrated after 26 and 25 months of therapy, respectively (table 3 ). In all three patients, an increase in cardiac index was observed during epoprostenol treatment, which was associated with an increase in $S_{\mathrm{v}}, \mathrm{O}_{2}$ in two patients (patient $\mathrm{B}$ and $\mathrm{C}$ ). In patient A, however, despite the fact that all haemodynamic parameters improved significantly during treatment, a decrease in $\mathrm{S}_{\mathrm{v}, \mathrm{O}_{2}}$ was documented. Although, due to its vasodilating properties, epoprostenol may have enhanced right-to-left shunting in this patient, the observed discrepancy was not fully understood.

Three patients reported clinical decline during the period of epoprostenol therapy (table 4); in one (patient $\mathrm{H}$ ), who reported slowly progressive symptoms over the 9-month period of therapy, a 15\% decrease in PVR (TPR 29\%) was demonstrated. At presentation at UCSD, however, despite an increase in cardiac index during epoprostenol treatment, this patient showed signs of overt right heart failure, which was haemodynamically reflected by an increased RAP and a decreased $S_{\mathrm{v}}, \mathrm{O}_{2}$. Two patients experienced haemodynamic and clinical decline over a 3-4-month period of epoprostenol administration (patients $\mathrm{G}$ and $\mathrm{I}$ ). This clinical decline was accompanied by a $32 \%$ and $18 \%$ increase in PVR (TPR 20\% and $12 \%$ ), respectively (table 3 ).

\section{Outcome of pulmonary thromboendarterectomy}

PTE resulted in substantial haemodynamic improvement compared with both the pre-epoprostenol and postepoprostenol values in all patients undergoing the procedure (fig. 1). The postoperative course was uncomplicated in all but three patients, two of whom experienced reperfusion lung injury and one who developed a nosocomial pneumonia.

Based on the preoperative haemodynamic, angiographic and angioscopic findings, residual pulmonary hypertension that may require continuation of epoprostenol postoperatively was anticipated in two patients and considered to be likely in three others. In the remaining four patients, discontinuation of epoprostenol after surgery was expected. However, all but two patients had a favourable haemodynamic response to thromboendarterectomy. Following thromboendarterectomy, the median (range) cardiac index rose from $1.9(1.1-2.9)$ to 2.7 $(2.0-3.6) \mathrm{L} \cdot \mathrm{min}^{-1} \cdot \mathrm{m}^{-2}$, the mPAP decreased from $48(40-61)$ to $22(15-40) \mathrm{mmHg}$, and the TPR decreased from 1,000 $(667-1,913)$ to $350(80-653) \mathrm{dyn} \cdot \mathrm{s}^{-1} \cdot \mathrm{cm}^{-5}$ (Wilcoxon signed rank test, all $\mathrm{p}<0.01)$. Accordingly, epoprostenol administration was weaned and ultimately discontinued in all but two patients (patients A and D) shortly after PTE.

In the two patients in whom epoprostenol therapy was unable to be discontinued postoperatively, dose reductions from 18 to $7 \mathrm{ng} \cdot \mathrm{kg}^{-1} \cdot \mathrm{min}^{-1}$ and from 29 to $14 \mathrm{ng} \cdot \mathrm{kg}^{-1} \cdot \mathrm{min}^{-1}$ were achieved, respectively.

\section{Discussion}

The data from this study indicate that selected patients with CTEPH may benefit clinically and haemodynamically from continuous intravenous epoprostenol treatment prior to PTE. However, factors predictive of a beneficial response, and whether this intervention influences either morbidity or mortality associated with thromboendarterectomy still remain to be established.

PTE represents the therapy of choice for patients with surgically accessible CTEPH [1, 2, 13]. Published reports have confirmed that this intervention is associated with improvement and, at times, normalisation of pulmonary haemodynamics, improvement in gas exchange and improvement in quality of life. This intervention, however, does not come without potential risk. Recently published mortality figures in patients undergoing PTE have ranged from $4.8-23.5 \%$ of operated cases [1]; the major causes of death attributable to reperfusion lung injury and residual pulmonary hypertension associated with right ventricular failure. Furthermore, as a result of the known diagnostic delays that accompany this disease process, patients may be in overt right ventricular failure at the time of diagnosis, placing them at potentially higher risk for preoperative and postoperative haemodynamic instability and death [14]. In this series, a mean delay of almost 14 months (median 12, range 6-36 months) occurred between symptom onset and diagnosis. Finally, patients are often encountered in whom the haemodynamic impairment seems disproportionate to the extent of accessible thromboembolic disease. In such patients, some degree of improvement but not normalisation of pulmonary haemodynamics can be anticipated following PTE. Failure to substantially lower the PVR following PTE may be associated with postoperative haemodynamic instability.

The effects of epoprostenol on the haemodynamic parameters observed in the present patients, in particular the increase in cardiac output, were similar to those in patients with PPH. In clinical studies of PPH [5, 6, 15], epoprostenol treatment tends to increase cardiac output more than it lowers PAP, an effect that correlated strongly with functional capacity and survival. The beneficial effects of epoprostenol in PAH may also be due to antiplatelet properties, inhibitory effects on vascular growth, or inotropic effects [16].

Recently, Nagaya et al. [17] reported their experience using continuous intravenous epoprostenol prior to PTE in patients with severe CTEPH, as defined by a PVR $>1,200 \mathrm{dyn} \cdot \mathrm{s}^{-1} \cdot \mathrm{cm}^{-5}$. Epoprostenol treatment in these patients resulted in a highly significant decrease in PVR, and an increase in cardiac output which was associated with a decrease in the plasma levels of brain natriuretic peptide, suggesting improvement of right ventricular performance. mPAP did not change significantly. Postoperative outcome was excellent in all but one patient who died because of persistent postoperative pulmonary hypertension. In fact, all patients studied showed a favourable response upon epoprostenol treatment. In view of these observations, this may indicate that the patient population studied represented a selection of CTEPH patients with severe pulmonary hypertension due to a major resistive component caused by a secondary arteriopathy. However, all but one epoprostenoltreated patient had an excellent postoperative outcome, suggesting that in most patients chronic thromboembolic disease was the key factor, responsible for the severity of their haemodynamic condition. In fact, the study by NAGAYA et al. [17] leaves the key question unanswered: did the patients have an excellent postoperative outcome because of the epoprostenol treatment or because of the skills of the surgeon? It would be also of interest to know whether the angiographic characteristics of the chronic thromboembolism differed between the epoprostenol treated and the untreated group studied by NAGAYA et al. [17].

In this series, patients with severe right ventricular dysfunction, characterised at right heart catheterisation by a 
low cardiac index, a low $\mathrm{S}_{\mathrm{v}} \mathrm{O}_{2}$, and an increased RAP, appeared to derive the greatest benefit from epoprostenol treatment. Three of the four patients with this haemodynamic profile achieved a striking clinical and haemodynamic response. In one patient (patient E), it cannot be excluded that part of the observed improvement was due to the concomitant start of anticoagulant treatment. However, angiographically there were signs of extensive proximal chronic thromboembolic disease only, without any sign of acute pulmonary embolism. Furthermore, the observed thromboembolic lesions did not change angiographically upon anticoagulant treatment. This observation is consistent with earlier observations in patients with PPH [18]. Also in these patients, the most severely impaired, defined by an $S_{\mathrm{v}}, \mathrm{O}_{2}$ of $<60 \%$, appeared to derive the greatest benefit from epoprostenol treatment [18].

Patients with CTEPH have several mechanisms responsible for their elevated PVR: the surgically accessible chronic thromboembolic disease, the surgically inaccessible thromboembolic disease, and the resistance conferred by a secondary, small vessel arteriopathy. That the latter mechanism contributes to the haemodynamic dysfunction has been supported by observations in lung biopsy specimens obtained at the time of PTE showing changes in the pulmonary microvasculature similar to those observed in other forms of PAH [19]. Furthermore, secondary pulmonary vascular remodelling has been demonstrated in a canine model of CTEPH [20]. It is this distal resistive component of CTEPH that is most likely to be responsive to epoprostenol treatment. Based on this supposition, it may be predicted that those patients who demonstrated the best response to epoprostenol may have achieved the least haemodynamic benefit from thromboendarterectomy. However, a comparison of the three positive epoprostenol responders (patients $\mathrm{D}-\mathrm{F}$ ) with the three negative responders (patients $\mathrm{G}-\mathrm{I}$ ) did not demonstrate a significant difference between groups in the absolute value of the postoperative TPR (255 \pm 216 versus $309 \pm 74)$, absolute reduction in TPR $(1,763 \pm 936$ versus $1,157 \pm 304)$, or per cent reduction in TPR ( $86 \pm 14$ versus $79 \pm 9$ ). Neither was a difference in angiographic characteristics between the groups identified.

These preliminary observations may have important implications for the future management of selected patients with CTEPH. If the findings of this study are validated, patients presenting with marginally accessible chronic thromboembolic disease and right-sided heart failure, thereby potentially predisposing them to a more complicated postoperative course and a higher postoperative mortality risk, may benefit from prethromboendarterectomy treatment with epoprostenol. The four patients in this study treated with epoprostenol because of clinical signs of overt right ventricular failure had an unremarkable postoperative course without any sign of haemodynamic instability. In the authors' view, pretreatment with epoprostenol is not indicated in patients that appear to have surgically accessible chronic thromboembolic disease that seems proportionate with the degree of pulmonary hypertension. However, selected patients with more complicated variants of CTEPH may benefit from preoperative medical therapy. Based upon these observations and those by NAGAYA et al. [17], the authors would suggest that future treatment trials should focus on CTEPH patients who have a higher perioperative mortality [14, 21], specifically those with signs of right ventricular failure or a severely increased PVR. Although the optimal duration of treatment remains undefined, a relatively short period of 2-4 months appears to be sufficient to cause a significant haemodynamic improvement. An important issue, however, that should be addressed in future studies is the potentially hazardous sideeffects of epoprostenol treatment in this group, particularly the incidence and severity of reperfusion pulmonary oedema that may occur after successful PTE. In addition, newer and less invasive treatment modalities that are effective in other forms of pulmonary hypertension, such as the nonselective endothelin-receptor antagonist bosentan [22] and the prostacyclin analogue iloprost, which can be administered by nebulisation [23], merit further evaluation in CTEPH. In a placebo-controlled, multicentre study [23], patients who inhaled iloprost for 12 weeks improved exercise capacity and pulmonary haemodynamics in severe pulmonary hypertension. This study included a substantial number of inoperable CTEPH patients. However, in contrast to the patients with PPH included in this study, the patients with non-PPH, including the CTEPH patients, did not appear to derive a clinically significant benefit from inhaled iloprost treatment.

These observations also warrant additional study in patients with inoperable thromboembolic disease in which epoprostenol may be useful as a "bridge to transplantation". Finally, patients with residual pulmonary hypertension following PTE, who are at risk for subsequent progression of pulmonary hypertension [2], may benefit from postoperative treatment with epoprostenol. Two studies using orally active drugs in patients with inoperable CTEPH were recently reported $[24,25]$. In a retrospective study, ONO et al. [24] showed that treatment with the orally active prostacyclin analogue, beraprost sodium, may be of benefit in patients with inoperable CTEPH. In a noncontrolled prospective study, GHOFRANI et al. [25] studied the effects on haemodynamics and exercise capacity of the phosphodiesterase type-5 inhibitor sildenafil. Treatment with sildenafil for $\sim 6$ months was associated with a significant improvement in both haemodynamics and exercise capacity. Both these observations further support the notion that treatments focusing on the secondary arteriopathy may be of benefit in CTEPH patients, although these observations need confirmation from larger, placebo-controlled trials.

A number of study limitations can be recognised. First, this study was performed in a retrospective manner and is therefore subject to limitations inherent in any retrospective analysis. Secondly, while all patients had severe pulmonary hypertension and right ventricular dysfunction at the time of presentation, objective criteria for initiation of epoprostenol therapy were not defined a priori. Thirdly, the limited number of patients studied make it impossible to identify angiographic and/or haemodynamic parameters that may predict a beneficial or adverse response to epoprostenol therapy. Fourthly, since no control group was included, it is impossible to determine whether the use of epoprostenol influenced the clinical course or perioperative morbidity or mortality in those patients who experienced a beneficial response.

Despite these limitations, these observations suggest that epoprostenol therapy can produce beneficial clinical and haemodynamic effects in a subset of patients with chronic thromboembolic pulmonary hypertension, and that the concurrent use of epoprostenol does not appear to adversely affect the postoperative course of patients who subsequently undergo pulmonary thromboendarterectomy.

\footnotetext{
Acknowledgements. The authors would like to thank M. Rubinfire (University of Michigan, Ann Arbor, MI, USA), J. Hauser (Westhaven, CT, USA), V. Tapson (Duke University, Durham, NC, USA) and J.F. Beamis (Burlington, MA, USA) for sharing the care of their patients.
}

\section{References}

1. Fedullo PF, Auger WR, Kerr KM, Rubin LJ. Chronic pulmonary hypertension. N Engl J Med 2001; 345: 14651471. 
2. Fedullo PF, Auger WR, Channick RN, Kerr KM, Rubin LJ. Chronic thromboembolic pulmonary hypertension. Clin Chest Med 2001; 22: 561-581.

3. Jones DK, Higenbottam TW, Wallwork J. Treatment of primary pulmonary hypertension with intravenous epoprostenol (prostacyclin). Br Heart J 1987; 57: 270-278.

4. Rubin LJ, Mendoza J, Hood M, et al. Treatment of primary pulmonary hypertension with continuous prostacyclin (epoprostenol). Results of a randomized trial. Ann Intern Med 1990; 112: 485-491.

5. Barst RJ, Rubin LJ, Long WA, et al. A comparison of continuous intravenous epoprostenol (prostacyclin) with conventional therapy in primary pulmonary hypertension. N Engl J Med 1996; 334: 296-301.

6. Shapiro SM, Oudiz RJ, Cao T, et al. Primary pulmonary hypertension: improved long-term effects and survival with continuous epoprostenol infusion. J Am Coll Cardiol 1997; 30: 343-349.

7. Badesch DB, Tapson VF, McGoon MD, et al. Continuous intravenous epoprostenol for pulmonary hypertension due to the sleroderma spectrum of the disease. A randomized, controlled trial. Ann Intern Med 2000; 132: 425-434.

8. McLaughlin VV, Genthner DE, Panella MM, Hess DM, Rich S. Compassionate use of continuous prostacyclin in the management of secondary pulmonary hypertension: a case series. Ann Intern Med 1999; 130: 740-743.

9. Rosenzweig EB, Kerstein D, Barst RJ. Long-term prostacyclin for pulmonary hypertension with associated congenital heart defects. Circulation 1999; 99: 1858-1865.

10. Aguilar RV, Farber HW. Epoprostenol (prostacyclin) therapy in HIV-associated pulmonary hypertension. $\mathrm{Am}$ J Respir Crit Care Med 2000; 162: 1846-1850.

11. Bakst AE, Gaine SP, Rubin LJ. Continuous intravenous epoprostenol therapy for pulmonary hypertension in Gaucher's disease. Chest 1999; 116: 1127-1129.

12. Kuo PC, Johnson LB, Plotkin JS, Howell CD, Bartlett ST, Rubin LJ. Continuous intravenous infusion of epoprostenol for the treatment of portopulmonary hypertension. Transplantation 1997; 63: 604-606.

13. Jamieson SW, Kapelanski DP. Pulmonary endarterectomy. Curr Probl Surg 2000; 37: 165-252.
14. Moser KM, Auger WR, Fedullo PF. Chronic major-vessel thromboembolic pulmonary hypertension. Circulation 1990; 81: $1735-1743$.

15. McLaughlin VV, Genthner DE, Panella MM, Rich S. Reduction in vascular resistance with long-term epoprostenol (prostacyclin) therapy in primary pulmonary hypertension. N Engl J Med 1998; 338: 273-277.

16. Galié N, Manes A, Branzi A. Medical therapy of pulmonary hypertension. The prostacyclins. Clin Chest Med 2001; 22: 529-537.

17. Nagaya N, Sasaki N, Ando M, et al. Prostacyclin therapy before pulmonary thromboendarterectomy in patients with chronic thromboembolic pulmonary hypertension. Chest 2003; 123: 338-343.

18. Cremona G, Higgenbottam T. Role of prostacyclin in the treatment of primary pulmonary hypertension. Am J Cardiol 1995; 75: 67A-71A.

19. Moser KM, Bloor CM. Pulmonary vascular lesions occurring in patients with chronic major-vessel thromboembolic pulmonary hypertension. Chest 1993; 103: 684-692.

20. Kim H, Yung GL, Marsh JJ, et al. Endothelin mediates pulmonary vascular remodeling in a canine model of chronic embolic pulmonary hypertension. Eur Respir $J$ 2000; 15: 640-648.

21. Hartz RS, Byrne JG, Levitsky S, Park J, Rich S. Predictors of mortality in pulmonary thromboendarterectomy. Ann Thorac Surg 1996; 62: 1255-1260.

22. Rubin LJ, Badesch DB, Barst RJ, et al. Bosentan for pulmonary arterial hypertension. N Engl J Med 2002; 346: 896-903.

23. Olschewski H, Simmoneau G, Galiè N, et al. Inhaled iloprost for severe pulmonary hypertension. $N$ Engl J Med 2002; 347: 322-329.

24. Ono F, Nagaya N, Okomura H, et al. Effect of orally active prostacyclin analogue on survival in patients with chronic thromboembolic pulmonary hypertension without major vessel component. Chest 2003; 123: 1583-1588.

25. Ghofrani HA, Schermuly RT, Rose F, et al. Sildenafil for long-term treatment of nonoperable chronic thromboembolic pulmonary hypertension. Am J Respir Crit Care Med 2003; 167: 1139-1141. 